\title{
Anfíbios anuros da região urbana de Altamira (Amazônia Oriental), Pará, Brasil
}

\author{
Sílvia Renata Knispel ${ }^{1}$ \\ Flávio Bezerra Barros ${ }^{2 *}$ \\ 'Universidade Federal do Pará, Campus de Altamira, Faculdade de Ciências Biológicas \\ Laboratório Integrado de Biologia e Educação Ambiental (LIBEA), Altamira - PA, Brasil \\ ${ }^{2}$ Universidade Federal do Pará, Campus de Altamira, Faculdade de Educação \\ Rua Cel. José Porfírio, 2515, São Sebastião, CEP 68372-040, Altamira - PA, Brasil \\ *Autor para correspondência \\ flaviobb@ufpa.br
}

Submetido em 15/09/2008

Aceito para publicação em 17/11/2008

\section{Resumo}

O presente estudo teve como objetivo inventariar as espécies de anuros em três localidades da região urbana de Altamira $\left(03^{\circ} 12^{\prime} \mathrm{S}\right.$, longitude $\left.51^{\circ} 12^{\prime} \mathrm{W}\right)$, município localizado no Oeste do Pará (Amazônia Oriental). As coletas foram realizadas entre janeiro e junho de 2004. Foram registradas 15 espécies durante o estudo. A família Hylidae foi a mais representada, com oito espécies registradas. Os dados foram compatíveis com o grau de conservação das áreas de coleta. A necessidade de realização de novos inventários faunísticos em todos os biomas brasileiros é de extrema urgência, particularmente na Amazônia, dada sua vasta extensão e carência de inventários.

Unitermos: Anura, inventário, estado do Pará, Amazônia

\section{Abstract}

Anuran amphibians of the urban region of Altamira (Oriental Amazonia), state of Pará, Brazil. The present study aimed to take stock of the species of anurans in three localities of the urban region of Altamira, a municipal district in the west of the state of Pará (Oriental Amazonia). Collections were made between January and June of 2004. Fifteen species were recorded during the study. The family Hylidae was the most represented, with eight species. The data was compatible with the degree of conservation of the collection areas. The necessity of making new fauna inventories in all Brazilian biomes is of extreme urgency, particularly in the Amazon, given its vast extension and lack of inventories.

Key words: anuran, inventory, state of Pará, Amazonia

\section{Introdução}

Atualmente são conhecidas mais de 6.300 espécies de anfíbios (Frost, 2008), das quais 5.600 são anuros, números que tendem a aumentar devido às constantes descobertas de novas espécies. O Brasil é o País que possui a maior diversidade específica de anuros, com mais de 800 espécies descritas até o presente momento (SBH, 2008), onde 60\% destas são endêmicas, isto é, exclusivas do Brasil (Feio et al., 1998; Lewinsohn e 
Prado, 2004; SBH, 2008). A Amazônia brasileira abriga um total de 163 espécies de anfíbios (Azevedo-Ramos e Galatti, 2001). Esses números devem aumentar na medida que várias espécies com situação taxonômica indefinida vão sendo descritas (Galatti, comunicação pessoal). De acordo com Azevedo-Ramos e Galatti (2001), apenas tem-se registro de 29 localidades inventariadas em toda a Amazônia brasileira.

Além de contribuir com o aumento do conhecimento acerca da fauna stricto sensu, os inventários são ferramentas essenciais para a implantação de Unidades de Conservação de importância biológica, social e econômica para muitas regiões, principalmente aquelas em que os impactos negativos ao meio ambiente são mais intensos. No caso de Altamira, município amazônico localizado no Oeste paraense, os principais impactos negativos são a perda da floresta pelas atividades madeireira e pecuária, além de queimadas e poluição de corpos d'água por substâncias provenientes de atividades garimpeira e agrícola. Porém, o mais relevante argumento para se inventariar a anurofauna amazônica é a importância que este grupo zoológico representa como bioindicador para os ecossistemas, além de uma infinidade de outras razões (Barros, 2005). Todavia, os anuros precisam constantemente se adaptar em ambientes modificados antropicamente para garantir a sobrevivência das espécies (Izecksohn e Carvalho-e-Silva, 2001).

Por causa das constantes mudanças e alterações no meio ambiente (ver Silvano e Segalla, 2005), a maioria dos anfíbios precisa se adaptar às novas condições de sobrevivência. Pelo fato desses animais apresentarem duas fases de vida, uma na água e outra na terra, mais rapidamente eles respondem a essas alterações ocorridas (ver, por exemplo, Blaustein e Kiesecker, 2002). E os meios urbanos, por serem regiões com maior influência antrópica, são os que mais facilmente extinguem micro ambientes favoráveis para os anuros.

Em diferentes regiões biogeográficas do mundo, nas últimas décadas, tem-se observado o declínio de algumas populações de anfíbios, o que leva à preocupação de que este componente possa estar relacionado não apenas a causas locais, mas também a mudanças globais recentes, como o aumento da radiação ultra-violeta e o efeito estufa (Stebbins e Cohen, 1995). De acordo com Tocher
(1998), os anfíbios podem ser importantes indicadores das condições de impacto de florestas por possuírem um ciclo bifásico, com adultos e larvas ocupando habitats separados, e podem ser indicadores da saúde geral de um ecossistema. O presente trabalho teve como objetivo inventariar a anurofauna da área urbana de Altamira.

\section{Material e Métodos}

O trabalho foi conduzido na área urbana de Altamira, Pará. Nesta região da Amazônia Oriental, a precipitação pluviométrica mensal variou entre $544,5 \mathrm{~mm}$ e $116,3 \mathrm{~mm}$, a temperatura média mensal foi de $27,10^{\circ} \mathrm{Ce}$ a umidade relativa em torno de $82 \%$ (INMET - Belém). As áreas de coleta selecionadas foram: a) UFPA/Campus

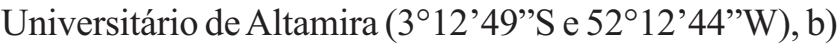

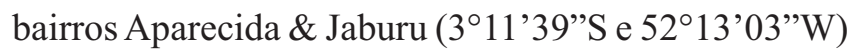
e c) Haras Wanderlan Cruz ( $3^{\circ} 14^{\prime} 02^{\prime \prime}$ 'S e $\left.52^{\circ} 13^{\prime} 36^{\prime \prime} \mathrm{W}\right)$. Aárea "a" tem grande influência antrópica, apresentando ambientes com presença de gramíneas, alguns arbustos e poucas árvores introduzidas, além do rio Xingu que margeia todo o campus. A área "b" corresponde a um sítio sem nenhuma vegetação, havendo simplesmente um aglomerado de residências, porém, no período chuvoso, há muita formação de ambientes favoráveis para a reprodução de anuros, como poças; além de um pequeno açude, que nesta época aumenta seu volume de água. Já o sítio "c" é formado de campo de pastagem e clareira, contando com a presença de muitas lagoas temporárias. As coletas ocorreram entre janeiro e junho de 2004, período chuvoso para o bioma amazônico. Para as amostragens da anurofauna, foi estabelecido apenas o procedimento de captura manual e observações visuais, no período noturno, entre 18:00 e 22:00 horas, totalizando 45 visitas ao campo, com um total aproximado de $180 \mathrm{~h}$ de observações. Os animais encontrados foram capturados e acondicionados em sacos plásticos com substrato local. Posteriormente, alguns indivíduos foram fotografados em vida. Em seguida os exemplares foram preparados de acordo com os padrões convencionais para anfíbios anuros (Calleffo, 2002). Os exemplares foram depositados na seção de Anfíbios da Coleção Herpetológica do Museu Paraense Emílio Goeldi (MPEG), sendo registrados com a seguinte numeração: 18617 MPEG a 18674 MPEG. 


\section{Resultados e Discussão}

No total foram coletados 58 indivíduos pertencentes a 15 espécies, distribuídas em oito gêneros e quatro famílias. A família Hylidae apresentou maior diversidade específica (oito espécies, 53,33\%) do total, seguida de Leptodactylidae e Bufonidae, ambas com a mesma diversidade (três espécies, 20\%) e Microhylidae (uma espécie, 6,33\%) (Tabela 1).

A diversidade de espécies encontrada na área urbana de Altamira pode ser considerada baixa se comparada a outras regiões da Amazônia brasileira, onde foram realizados inventários de anuros. Por exemplo, na Floresta Nacional de Caxiuanã, no Pará, houve um registro de 29 espécies de anuros (Ávila-Pires e Hoogmoed, 1997); na Estação Científica Ferreira Penna, também na Floresta Nacional (FLONA) de Caxiuanã, em outra ocasião, 29 espécies foram registradas (Bernardi, 1999). Estupiñán-T et al. (2002) registraram 35 espécies na região da FLONA de Caxiuanã e na Amazônia Central, ao norte de Manaus, 61 espécies foram identificadas por Tocher (1998).
Essa diferença no número de espécies, no caso de Altamira, possivelmente se deve ao fato da região inventariada sofrer constantemente modificações pela ação antrópica, bem como ao pequeno espaço de tempo (06 meses da estação chuvosa) de observações e coletas, e ainda o baixo esforço amostral. Contudo, um período de estudo mais longo nessa região poderá mostrar uma lista mais ampliada. Assim, ressaltamos a necessidade de se realizar outros inventários nessa região para possíveis comparações. Outro aspecto relevante que deve ser levado em consideração é que, em se tratando de Amazônia (e de qualquer outro bioma), possivelmente uma área urbana, mesmo que tenha influência de floresta primária e/ou de corpos d'água significativos, apresentará um total no número de espécies menor do que o encontrado em áreas naturais sem influência antrópica. Tocher (1998), por exemplo, observou a diferença na composição das espécies de anuros na Amazônia Central, catalogando 61 espécies para floresta primária e 24 em campo de pastagem, indicando que o desmatamento resulta em perda de espécies de anfíbios associados à floresta.

TABELA 1: Lista de espécies registradas nos ambientes das três áreas de amostragem da área urbana de Altamira/ PA. Localidades: Haras Wanderlan Cruz $=$ HWC, UFPA/ Campus Universitário de Altamira $=$ CUA e Bairro Aparecida \& Jaburu = BAJ.

\begin{tabular}{|c|c|c|c|c|}
\hline Família & Gênero e espécie & HWC & CUA & BAJ \\
\hline \multirow[t]{3}{*}{ Bufonidae } & Rhaebo guttatus & & & $\mathrm{x}$ \\
\hline & Rhinella granulosa & $\mathrm{x}$ & & \\
\hline & Rhinella marina & $\mathrm{x}$ & $\mathrm{x}$ & $\mathrm{x}$ \\
\hline \multirow[t]{8}{*}{ Hylidae } & Dendropsophus minusculus & $\mathrm{x}$ & & \\
\hline & Dendropsophus sarayacuensis & & & $\mathrm{x}$ \\
\hline & Hypsiboas sp. (1) & $\mathrm{x}$ & & \\
\hline & Trachycephalus venulosus & $\mathrm{x}$ & & $\mathrm{x}$ \\
\hline & Scinax cf. $x$-signatus & $\mathrm{x}$ & & \\
\hline & Scinax sp. (1) & $\mathrm{x}$ & & $\mathrm{x}$ \\
\hline & Scinax sp. (2) & $\mathrm{x}$ & $\mathrm{x}$ & \\
\hline & Scinax trilineatus & $\mathrm{x}$ & & \\
\hline \multirow[t]{3}{*}{ Leptodactylidaedae } & Leptodactylus macrosternum & $\mathrm{x}$ & $\mathrm{x}$ & $\mathrm{x}$ \\
\hline & Leptodactylus pentadactylus & $\mathrm{x}$ & & \\
\hline & Leptodactylus petersii & & & $\mathrm{x}$ \\
\hline Microhylidae & Elachistocleis ovalis & $\mathrm{x}$ & $\mathrm{x}$ & $\mathrm{x}$ \\
\hline Total & & 12 & 04 & 08 \\
\hline
\end{tabular}


Se comparadas as três áreas de coleta neste estudo quanto ao grau de influência antrópica, total de sítios apropriados para reprodução, bem como o estado de conservação desses ambientes em cada localidade, o Haras Wanderlan foi a área que apresentou o maior número de microambientes favoráveis para a reprodução de anuros, bem como mais conservados. De fato, isso pôde ser comprovado na medida em que se registrou para esta área 12 espécies. Esses dados se apresentam compatíveis com o grau de conservação das áreas de coleta, sendo a UFPA a localidade com menor número de ambientes (corpos d'água) e com maior influência de atividades humanas.

De acordo com Izecksohn e Carvalho-e-Silva (2001), as populações de anfíbios que habitam áreas urbanas sofrem ameaça de desaparecimento, principalmente devido à poluição e extinção de habitats apropriados para a reprodução e sobrevivência dos anuros.

A necessidade de realização de novos inventários faunísticos em todos os biomas brasileiros é de extrema urgência, particularmente na Amazônia, dada sua vasta extensão e carência de inventários. Tal urgência se deve principalmente por conta da rápida perda dos habitats propícios para a existência dos anuros, como o interior das florestas e corpos de água.

\section{Agradecimentos}

Ao Dr. Marinus S. Hoogmoed, do MPEG, pela identificação dos exemplares. À $\mathrm{Dr}^{\mathrm{a}}$ Ana Prudente, do MPEG, por receber o material coletado na Coleção Herpetológica dessa Instituição. Ao IBAMA, pela liberação da licença de coleta (licença ${ }^{\circ}$ 052/04-RAN). Ao Sr. Wanderlan Cruz, pela permissão para a realização de coletas no Haras Wanderlan. Ao Edimar Santana, pelo apoio no trabalho de campo. Aos dois revisores anônimos pelas importantes sugestões ao manuscrito.

\section{Referências}

Ávila-Pires, T. C. S.; Hoogmoed, M. S. 1997. The Herpetofauna. In: Lisboa, P. L. B. (Org.). Caxiuanã. Museu Paraense Emílio Goeldi, Belém, Brasil, p.389-401.
Azevedo-Ramos, C.; Gallati, U. 2001. Relatório técnico sobre a diversidade de anfíbios na Amazônia Brasileira. In: Capobianco, J. P. R.; Veríssimo, A.; Moreira, A.; Sawyer, D.; Santos, I. dos \& Pinto, L. P. (Eds). Biodiversidade na Amazônia Brasileira. Avaliação e ações prioritárias para a conservação, uso sustentável e repartição de benefícios. Editora Estação Liberdade, Instituto Socioambiental, São Paulo, Brasil, p.79-88.

Barros, F. B. 2005. Sapos e seres humanos: Uma relação de preconceitos? Textos do Núcleo de Estudos Integrados Sobre Agricultura Familiar, 9: 1-11.

Blaustein, A. R.; Kiesecker, J. M. 2002. Complexity in conservation: lessons from the global decline of amphibian populations. Ecology Letters, 5: 597-608.

Bernardi, J. A. R. 1999. Composição e diversidade de espécies da anurofauna da Estação Científica Ferreira Penna, Floresta Nacional de Caxiuanã, Pará, Brasil. Dissertação de Mestrado, Universidade Federal do Pará e Museu Paraense Emílio Goeldi, Belém, Brasil, 126pp.

Calleffo, M. E. V. 2002. Anfíbios. In: Auricchio, P. \& Salomão, M. da G. (Orgs). Técnicas de coleta e preparação de vertebrados para fins científicos e didáticos. Instituto Pau Brasil de História Natural, São Paulo, Brasil, p.45-73.

Estupiñán-T, R. A.; Bernardi, J. A. R.; Gallati, U. 2002. Fauna Anura. In: Lisboa, P. L. B. (Org.). Populações tradicionais, meio físico \& diversidade biológica: Caxiuanã. Museu Paraense Emílio Goeldi, Belém, Brasil, p.541-553.

Feio, R. N.; Braga, U. M. L.; Wiederhecker, H.; Santos, P. S. 1998. Anfíbios do Parque Estadual do Rio Doce (Minas Gerais). Universidade Federal de Viçosa, Instituto Estadual de Florestas, Viçosa, Brasil, 32pp.

Frost, D. R. 2008. Amphibian species of the world 5.2-An on line reference. Disponível em <http://research.amnh.org/herpetology/ amphibia/index.php>. Acesso em 31 de agosto de 2008.

Izecksohn, E.; Carvalho-e-Silva, S. P. 2001. Anfíbios do município do Rio de Janeiro. Editora UFRJ, Rio de Janeiro, Brasil, 148pp.

Lewinsohn, T. M.; Prado, P. I. 2004. Biodiversidade brasileira: Síntese do estado atual do conhecimento. Editora Contexto, São Paulo, Brasil, 176pp.

SBH. 2008. Brazilian amphibians - List of species. Disponível em $<$ http://www.sbherpetologia.org.br $>$. Acesso em 3 de setembro de 2008.

Silvano, D. E. L.; Segalla, M. V. 2005. Conservação de anfíbios no Brasil. Megadiversidade, 1: 79-86.

Stebbins, R. C.; Cohen, N. W. 1995. A natural history of amphibians. Princeton University Press, New Jersey, USA, 646pp.

Tocher, M. D. 1998. Diferenças na composição de espécies de sapos entre três tipos de floresta e campo de pastagem na Amazônia Central. In: Gascon, C. \& Moutinho, P. (Eds). Floresta Amazônica: Dinâmica, regeneração e manejo. Ministério da Ciência e Tecnologia, Instituto Nacional de Pesquisas da Amazônia, Manaus, Brasil, p.219-232. 